\title{
World Health Organization Drug Dictionary
}

National Cancer Institute

\section{Source}

National Cancer Institute. World Health Organization Drug Dictionary. NCI Thesaurus.

Code $C 49475$.

A reference source of drugs and drug associated information maintained by the World Health Organization. 